\title{
Allelic variation of soybean flower color gene $W 4$ encoding dihydroflavonol 4-reductase 2
}

\author{
Fan Yan ${ }^{1}$, Shaokang Di ${ }^{1}$, Felipe Rojas Rodas ${ }^{1}$, Tito Rodriguez Torrico ${ }^{1}$, Yoshinori Murai ${ }^{2}$, Tsukasa Iwashina ${ }^{2}$, \\ Toyoaki Anai ${ }^{3}$ and Ryoji Takahashi ${ }^{1,4^{*}}$
}

\begin{abstract}
Background: Flower color of soybean is primarily controlled by six genes, viz., W1, W2, W3, W4, Wm and Wp. This study was conducted to investigate the genetic and chemical basis of newly-identified flower color variants including two soybean mutant lines, 222-A-3 (near white flower) and E30-D-1 (light purple flower), a near-isogenic line (Clark-w4), flower color variants (T321 and T369) descended from the w4-mutable line and kw4 (near white flower, Glycine soja).

Results: Complementation tests revealed that the flower color of 222-A-3 and kw4 was controlled by the recessive allele (w4) of the W4 locus encoding dihydroflavonol 4-reductase 2 (DFR2). In 222-A-3, a single base was deleted in the first exon resulting in a truncated polypeptide consisting of 24 amino acids. In Clark-w4, base substitution of the first nucleotide of the fourth intron abolished the $5^{\prime}$ splice site, resulting in the retention of the intron. The DFR2 gene of kw4 was not expressed. The above results suggest that complete loss-of-function of DFR2 gene leads to near white flowers. Light purple flower of E30-D-1 was controlled by a new allele at the W4 locus, w4-Ip. The gene symbol was approved by the Soybean Genetics Committee. In E30-D-1, a single-base substitution changed an amino acid at position 39 from arginine to histidine. Pale flowers of T369 had higher expression levels of the DFR2 gene. These flower petals contained unique dihydroflavonols that have not yet been reported to occur in soybean and G. soja.

Conclusions: Complete loss-of-function of DFR2 gene leads to near white flowers. A new allele of the W4 locus, w4-Ip regulates light purple flowers. Single amino acid substitution was associated with light purple flowers. Flower petals of T369 had higher levels of DFR2 gene expression and contained unique dihydroflavonols that are absent in soybean and G. soja. Thus, mutants of the DFR2 gene have unique flavonoid compositions and display a wide variety of flower color patterns in soybean, from near white, light purple, dilute purple to pale.
\end{abstract}

Keywords: Dihydroflavonol 4-reductase, Flavonoid, Flower color, Glycine max, Glycine soja, Soybean

\section{Background}

Flower color of soybean (Glycine $\max (\mathrm{L}$.$) Merr.) is pri-$ marily controlled by six genes (W1,W2,W3,W4, Wm and $W p$ ) [1,2]. Under $W 1$ genotype, soybean genotype with $W 3 W 4$ has dark purple, W3w4 has dilute purple or purple throat, $w 3 W 4$ has purple, and $w 3 w 4$ has near white flowers [3]. Flower color of genotypes with allelic combination W1w3w4 was indistinguishable from those with white flowers under many environments, suggesting

\footnotetext{
* Correspondence: masako@affrc.go.jp

${ }^{1}$ Graduate School of Life and Environmental Sciences, University of Tsukuba, Tsukuba, Ibaraki 305-8518, Japan

${ }^{4}$ National Institute of Crop Science, Tsukuba, Ibaraki 305-8518, Japan

Full list of author information is available at the end of the article
}

that environments affect flower color under the allelic combination [3]. W3 and W4 encode dihydroflavonol 4-reductase (DFR) [4,5]. W1, W2, Wm and Wp encode flavonoid 3'5'-hydroxylase, MYB transcription factor, flavonol synthase and flavanone 3-hydroxylase, respectively [6-10]. The roles of these genes in the biosynthesis of anthocyanin and flavonol are presented in Figure 1.

The flavonoids in flower petals of soybean were analyzed [11-13]. The primary components of anthocyanin were malvidin 3,5-di-O-glucoside, petunidin 3,5-di-O-glucoside, delphinidin 3,5-di-O-glucoside and delphinidin 3-O-glucoside. In addition, eight flavonol glycosides, kaempferol 3$O$-gentiobioside, kaempferol 3-O-rutinoside, kaempferol 3-O-glucoside, kaempferol 3-O-glycoside, kaempferol 3- 


\section{3 x Malonyl-CoA \\ $+$ \\ 4-Coumaroyl-CoA \\ $\downarrow$ CHS}

Flavanone

\begin{tabular}{l|l}
$W p$ & $\mathrm{~F} 3 \mathrm{H}$ \\
& $\mathrm{F}^{\prime} \mathrm{H}$ \\
$W 1$ & $\mathrm{~F}^{\prime} 5^{\prime} \mathrm{H}$
\end{tabular}

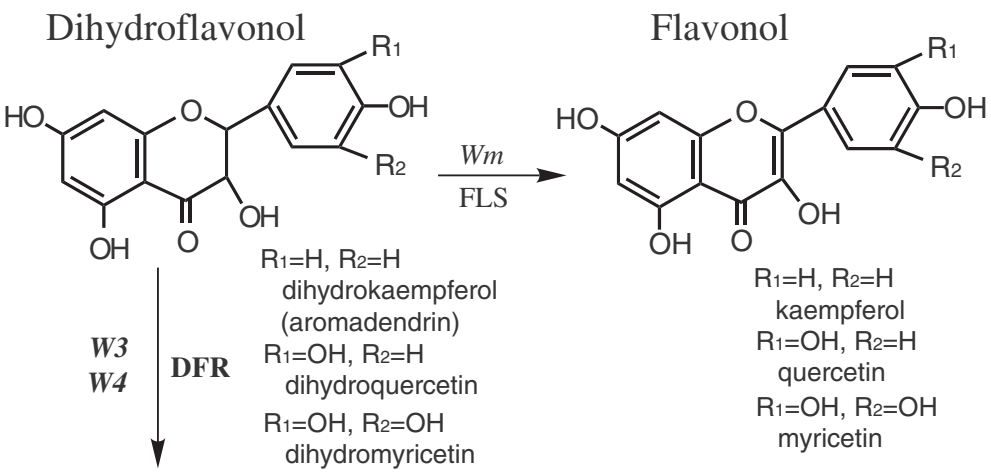

Leucoanthocyanidin<smiles>[R]c1cc(C2Oc3cc(O)cc(O)c3C(O)C2O)cc([R])c1O</smiles>

Anthocyanidin

Figure 1 Schematic diagram of the anthocyanin and flavonol biosynthetic pathways. Enzyme names are abbreviated as follow: chalcone synthase (CHS), chalcone isomerase (CHI), flavanone 3-hydroxylase (F3H), dihydroflavonol 4-reductase (DFR), flavonoid 3'-hydroxylase (F3'H), flavonoid $3^{\prime} 5^{\prime}$-hydroxylase $\left(F 3^{\prime} 5^{\prime} H\right)$, flavonol synthase $(F L S)$, leucoanthocyanidin dioxygenase (LDOX). Soybean flower color genes encoding the enzymes are in italic font.

O-rhamnosyl-( $1 \rightarrow 2)$-[glucosyl-( $1 \rightarrow 6)$-galactoside], kaempferol 7-O-glucoside, kaempferol 7-O-diglucoside and quercetin 3-O-gentiobioside, and one dihydroflavonol, aroma dendrin 3-O-glucoside were identified. No anthocyanins were detected in Clark-w1, a near-isogenic line (NIL) of US cultivar Clark at the W1 locus. Anthocyanins were not detected in a Clark- $w 4$ in 2003 and 2004, but trace amounts were detected in 2007 [11,12], indicating slight responsiveness to environmental conditions in agreement with the previous report [3].

A mutable allele of the W4 locus was discovered in a cross between two experimental lines with white and purple flowers, respectively [14]. The mutant line was designated as T322, and the mutable allele was designated as $w 4-m$. Mutant lines T321 with $w 4-d p$ allele (dilute purple flower) and T369 with $w 4-p$ allele (pale flower) were isolated from descendants of T322 [15,16] (Figure 2). A 20.5-kb transposable element ( $\operatorname{Tgm} 9$ ) was isolated from the second intron of the DFR2 gene [5]. In T321 and T369, $\operatorname{Tgm} 9$ was excised from the second intron, leaving behind 4- and 0-bp footprints, respectively [5]. A 5' end fragment of $\operatorname{Tgm} 9$ (944 bp) was integrated at a position $1043 \mathrm{bp}$ upstream of the transcription start site in T321. A fragment of $\operatorname{Tgm} 9$ was inserted at a position $1034 \mathrm{bp}$ upstream of the transcription start site in T369. Soybean has two other DFR genes, DFR1 and DFR3 [17]. DNA marker analysis suggested that W3 locus might correspond to the DFR1 [17]. 


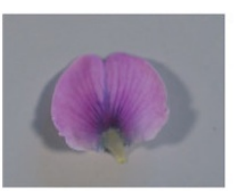

Clark (purple)

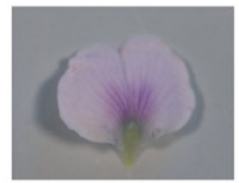

E30-D-1

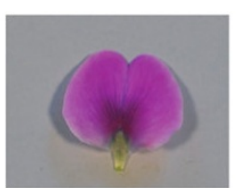

Bay (purple)

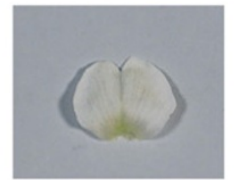

kw4

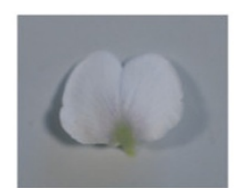

Clark-w4 (near white)

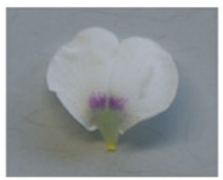

T321

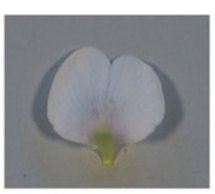

222-A-3 (near white)

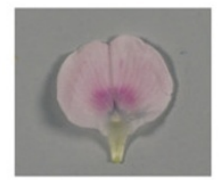

T369 (light purple) (near white) (dilute purple) (pale)

Figure 2 Banner petals of flower color variants of soybean and Glycine soja.

Flower color of the wild relative of soybean, Glycine soja Sieb. \& Zucc. is almost exclusively purple; by contrast, $33 \%(5,544$ out of 16,855$)$ of the soybean accessions in the USDA Soybean Germplasm Collections have white flowers (Dr. R.L. Nelson, personal communication 2006). One white-flowered plant was found in 1998 among the progeny of a purple-flowered G. soja accession that was introduced from South Korea [18]. Genetic analysis indicated that the white flower was caused by a recessive allele at the W1 locus similar to the white-flowered soybeans [18]. The mutation may have occurred during propagation at USDA. In 2002, a variant with light purple flowers, B09121 was discovered in southern Japan [13]. Genetic analysis suggested the light purple color was controlled by a new allele at the $W 1$ locus, $w 1-l p$. Flower petals of B09121 contained lower amounts of the four major anthocyanins common in purple flowers and contained small amounts of the $5^{\prime}$-unsubstituted versions of the abovementioned anthocyanins, peonidin 3,5-di-O-glucoside, cyanidin 3,5-di-O-glucoside and cyanidin 3-Oglucoside [13]. B09121 may be the first example of a flower color variant of G. soja found in nature.

Lines varying in flower color were obtained from mutagenized populations of US cultivar Bay. Line 222A-3 with near white flowers was isolated from an X-ray treated population, whereas line E30-D-1 with light purple flowers was developed from an EMS-treated population [19] (Figure 2). Dr. Donghe Xu (JIRCAS, Japan) found kw4, a G. soja accession with near white flowers, among accessions introduced from South Korea (personal communication, 2007) (Figure 2). It is unknown if the accession has near white flowers in the natural habitat. This study was conducted to investigate the genetic and chemical basis of flower color variants in G. $\max$
(Clark-w4, T321, T369, 222-A-3 and E30-D-1) and in G. soja (kw4).

\section{Methods}

\section{Genetic analysis}

The plant materials used in this study are listed in Table 1. US cultivars, Clark and Bay, have purple flowers $(W 1 W 2 w 3 W 4 W m W p)$. Clark has tawny $(T)$ and Bay has gray pubescence $(t)$. 222-A-3 and E30-D-1 were crossed with Clark-w4 (L68-1774, near white flower and tawny pubescence, W1W2w3w4WmWpT). E30-D-1 was also crossed with Clark. Flowers of 222-A-3 and E30-D-1 were emasculated one day before opening and fertilized with pollen from Clark or Clark-w4. A NIL of a Canadian cultivar Harosoy with $w 4$ allele, Harosoy-w4 (L72-1138, near white flower and gray pubescence, $W 1 W 2 w 3 w$ $4 \mathrm{Wm} W p t$ ) was crossed with kw4 (tawny pubescence). Hybridity of the $\mathrm{F}_{1}$ plants was ascertained by tawny pubescence color. Seeds of NILs, T321 and T369 were provided by the USDA Soybean Germplasm Collection. The NILs were developed by backcrossing the near white flower trait six times from the cultivar Laredo into Clark or Harosoy (Table 1) [20].

A total of seven $F_{1}$ and $130 F_{2}$ seeds derived from Harosoy-w4 $\times$ kw4 were field-planted on June 12 in 2009 at the National Institute of Crop Science, Tsukuba, Japan $\left(36^{\circ} 06^{\prime} \mathrm{N}, 140^{\circ} 05^{\prime} \mathrm{E}\right)$. Similar numbers of $\mathrm{F}_{1}$ and $\mathrm{F}_{2}$ seeds derived from two crosses (222-A-3 $\times$ Clark-w4 and E30-D$1 \times$ Clark-w4) were planted on June 10 in 2010. A bulk of 30 seeds each of fifty $F_{3}$ families derived from E30-D-1 $\times$ Clark-w4 were planted on June 7 in 2012 and June 10 in 2013. A total of six $F_{1}$ and $130 F_{2}$ seeds derived from E30D-1 $\times$ Clark were planted on June 10 in 2013. N, P and K were applied at $3.0,4.4$ and $8.3 \mathrm{~g} \mathrm{~m}^{-2}$, respectively. Plants 
Table 1 Plant materials of soybean and Glycine soja used in this study

\begin{tabular}{|c|c|c|c|c|}
\hline Line & Flower color & Genotype & Origin & Cross combination (Year of crossing) \\
\hline Clark & Purple & W1W2W3W4WmWpT & - & - \\
\hline Bay & Purple & W1W2w3W4WmWpt & - & - \\
\hline L68-1774 (Clark-w4) & Near white & W1W2w3w4WmWpT & $\mathrm{L}^{\mathrm{a}}(6) \times($ Laredo $\times$ Harosoy $)$ & - \\
\hline L72-1138 (Harosoy-w4) & Near white & W1W2w3w4WmWpt & $\mathrm{L}^{\mathrm{b}}(6) \times$ Laredo & - \\
\hline $222-A-3$ & Near white & - & X-ray induced mutant of Bay & $222-\mathrm{A}-3 \times$ Clark-w4 (2007) \\
\hline \multirow[t]{2}{*}{ E30-D-1 } & Light purple & - & EMS-induced mutant of Bay & E30-D-1 × Clark (2012) \\
\hline & & & & E30-D-1 × Clark-w4 (2008) \\
\hline kw4 & Near white & - & G. soja accession of South Korea & Harosoy-w4 × kw4 (2008) \\
\hline T321 & Dilute purple & W1W2w3w4-dpWmWpt & Germinal revertant derived from T322 & - \\
\hline T369 & Pale & W1W2w3w4-pWmWpt & Germinal revertant derived from T322 & - \\
\hline
\end{tabular}

${ }^{a}$ A Phytophtora and pustle-resistant Clark isoline with genes Rps1 and $r x p$.

${ }^{\mathrm{b}} \mathrm{A}$ Phytophtora and pustle-resistant Harosoy isoline with genes Rps1 and rxp.

were individually grown with spacing of $70 \mathrm{~cm}$ between rows and $10 \mathrm{~cm}$ between plants. Flower color was recorded in individual $\mathrm{F}_{1}, \mathrm{~F}_{2}$ and $\mathrm{F}_{3}$ plants.

\section{Analysis of flavonoids}

Banner petals were collected at the day of opening from field-grown plants in 2008. Three $200 \mathrm{mg}$ samples of banner petals were collected in $2 \mathrm{ml}$ of $\mathrm{MeOH}$ containing $0.1 \%(\mathrm{v} / \mathrm{v}) \mathrm{HCl}$ for anthocyanin analysis. Three $200 \mathrm{mg}$ samples in $2 \mathrm{ml}$ of absolute $\mathrm{MeOH}$ were also collected for the determination of flavonol and dihydroflavonol. High performance liquid chromatography (HPLC) of anthocyanins, flavonols and dihydroflavonol was performed following previously described protocols [11]. The $2 \mathrm{ml}$ extracts were filtered through disposable filtration units (Maishoridisc $\mathrm{H}-13-5$, Tosoh) and $10 \mu \mathrm{l}$ from each sample was subjected to HPLC analysis. The amount of flavonoids was estimated from the pertinent peak area in the HPLC chromatogram (detection wavelength of anthocyanins = $530 \mathrm{~nm}$; flavonols $=351 \mathrm{~nm}$; dihydroflavonols $=290 \mathrm{~nm}$ ). The peak area was subjected to analysis of variance using the Statistica software (StatSoft).

\section{Molecular cloning}

Total RNA was extracted from banner petals $(200 \mathrm{mg}$ ) using the TRIZOL Reagent (Invitrogen) according to the manufacturer's instructions. cDNA was synthesized by reverse transcription of $5 \mu \mathrm{g}$ of total RNA using the Superscript III First-Strand Synthesis System (Invitrogen) and an oligo $(\mathrm{dT})$ primer according to the manufacturer's instructions. The full-length cDNA was cloned by end-toend PCR from the plant materials using a pair of PCR primers shown in Table 2. The PCR mixture contained $0.5 \mu \mathrm{g}$ of cDNA, $10 \mathrm{pmol}$ of each primer, $10 \mathrm{pmol}$ of nucleotides and 1 unit of ExTaq in $1 \times$ ExTaq Buffer supplied by the manufacturer in a total volume of $50 \mu \mathrm{l}$. A $5 \mathrm{~min}$ denaturation at $94^{\circ} \mathrm{C}$ was followed by 30 cycles of $30 \mathrm{sec}$ denaturation at $94^{\circ} \mathrm{C}, 1 \mathrm{~min}$ annealing at $59^{\circ} \mathrm{C}$ and $1 \mathrm{~min}$ extension at $72^{\circ} \mathrm{C}$. A final $7 \mathrm{~min}$ extension at $72^{\circ} \mathrm{C}$ completed the program. The PCR was performed in an Applied Biosystems 9700 thermal cycler. The PCR products were cloned into $\mathrm{pCR} 2.1$ vector (Invitrogen) and sequenced. To evaluate the approximate size of PCR amplicons, PCR products were separated on a $2 \%$ agarose gel and visualized by EtBr staining.

Genomic DNA was isolated from trifoliolate leaves by $\mathrm{CTAB}$ [21]. Genome sequences containing the entire coding region (about $3.3 \mathrm{~kb}$ ) and the $5^{\prime}$ upstream region (about $1.2 \mathrm{~kb}$ ) of Clark and $\mathrm{kw} 4$ were determined by cloning two fragments overlapping each other using the PCR primers listed in Table 2. The $5^{\prime}$ upstream region was also cloned from Bay and E30-D-1. The PCR mixture contained $10 \mathrm{ng}$ of genomic DNA, 10 pmol of each primer, 10 pmol of nucleotides and 1 unit of ExTaq in $1 \times$ ExTaq Buffer in a total volume of $50 \mu$ l. The PCR products were cloned into the pCR 2.1 vector.

\section{Sequencing analysis}

Nucleotide sequences of both strands were determined with the BigDye terminator cycle method using an ABI3100 Genetic Analyzer (Applied Biosystems). Primers are exhibited in Table 2. Nucleotide sequences and the putative amino acid translations were analyzed with GENETYX ver. 8.1.2 (GENETYX). Sequences were aligned using ClustalW (http://clustalw.ddbj.nig.ac.jp/ index.php?lang=ja) at default settings.

\section{CAPS analysis}

Genomic DNA of Clark-w4, E30-D-1 and $40 \mathrm{~F}_{2}$ plants that were used for $\mathrm{F}_{3}$ progeny tests were isolated from trifoliolate leaves by CTAB. A pair of PCR primers (Table 2) was designed to detect a single-base substitution found in E30-D-1. The base substitution within the restriction site would result in the presence/absence of 
Table 2 PCR primers used in this study

\begin{tabular}{|c|c|c|c|}
\hline Purpose & Target & Forward primer $\left(5^{\prime}-3^{\prime}\right)$ & Reverse primer $\left(5^{\prime}-3^{\prime}\right)$ \\
\hline cDNA cloning & DFR2 & AACCAAAACAACGAGAGAGA & CTTATCCCTGATATGAAAGC \\
\hline \multirow[t]{3}{*}{ cDNA sequencing } & & TGCTAGACATCATGAAAGCA & TGTGAACAGCATATGTACCT \\
\hline & DFR2 & СACTGCTCTTTCACTAATCA & GATTAGTGAAAGAGCAGTGA \\
\hline & & TACCCTGAGTATAATGTCCT & TTCACGCATGCTITCATGAT \\
\hline \multirow[t]{2}{*}{ Cloning of genomic fragment } & Upstream fragment of DFR2 & ACGGTTTCTTCCATTCCATT & ACTTGATTTCAGCCATGGTA \\
\hline & Downstream fragment of DFR2 & GTTCATCAATGCACATAGAC & CTTATCCCTGATATGAAAGC \\
\hline \multirow[t]{6}{*}{ Sequencing of genomic fragment } & Upstream fragment of DFR2 & TACAAGTTGTCATCACGATC & GAAGCTTTGATGAAGCCATT \\
\hline & & TTTGGTGTACACTCGTATGT & CACAATTATATCATTGGGCA \\
\hline & & ATGTAACATGATGGTTCGTG & AACCACCATTGCTTAATACC \\
\hline & Downstream fragment of DFR2 & CTITTCTCTGCAGGTTCA & TAGTGGATGAATATGATTCT \\
\hline & & AAGTACCATTCCAACATTAA & GATAGATGACAGTTGTTGTC \\
\hline & & TGTTGTGCTCTITGGCATAT & ACCCTGAGTATAATGTCCTT \\
\hline CAPS analysis & DFR2 & ACGGTTTCTTCCATTCCATT & CAAATGCTTCACCTTCTTCA \\
\hline \multirow[t]{2}{*}{ Cloning of $5^{\prime}$ upstream region } & Upstream fragment of DFR2 & AGAGATATATAAGAAGTTAGGA & TATCACGAAATAGTTITTGTAAT \\
\hline & Downstream fragment of DFR2 & CCTITACCATCTACAAGATAA & ATGATGTAATATTGGGAACCT \\
\hline Sequencing of $5^{\prime}$ upstream region & DFR2 & GAAAAGAGAAATAGGTATTATA & GTTAACTAATCAAACTAAATT \\
\hline \multirow[t]{2}{*}{ Real-time PCR } & DFR2 & CCAAGGACCCTGAGAATGAA & CAGAAGTCAACATCGCTCCA \\
\hline & Actin & GTCCTTTCAGGAGGTACAACC & CCACATCTGCTGGAAGGTGC \\
\hline
\end{tabular}

the restriction site of $B s r G I$ in the amplified product. The PCR mixture contained $30 \mathrm{ng}$ of genomic DNA, 5 pmol of each primer, $10 \mathrm{pmol}$ of nucleotides and 1 unit of ExTaq in $1 \times$ ExTaq Buffer supplied by the manufacturer (Takara Bio) in a total volume of $25 \mu \mathrm{l}$. After an initial $30 \mathrm{sec}$ denaturation at $94^{\circ} \mathrm{C}$, there were 30 cycles of $30 \mathrm{sec}$ denaturation at $94^{\circ} \mathrm{C}, 1 \mathrm{~min}$ annealing at $56^{\circ} \mathrm{C}$ and $1 \mathrm{~min}$ extension at $72^{\circ} \mathrm{C}$. A final $7 \mathrm{~min}$ extension at $72^{\circ} \mathrm{C}$ completed the program. The amplified products were digested with BsrGI, and the digests were separated on an $8 \%$ nondenaturing polyacrylamide gel in $1 \times$ TBE buffer (90 mM Tris-borate, $2 \mathrm{mM}$ EDTA, $\mathrm{pH}$ 8.0). After electrophoresis, the gel was stained with ethidium bromide and the DNA fragments were visualized under UV light.

\section{Quantitative real-time PCR}

For quantitative real-time PCR, total RNA (5 $\mu \mathrm{g}$ ) from each of three replicate banner petal samples was reversetranscribed using the Superscript III First-Strand Synthesis System and an oligo d(T) primer. Primer sequences are exhibited in Table 2. The PCR mixture contained $0.4 \mu \mathrm{l}$ of cDNA synthesis reaction mixture, $6 \mathrm{pmol}$ of each primer, $1 \times$ ROX reference dye, $1 \times$ SYBR Premix Dimer Eraser (Takara Bio) and water to a final volume of $20 \mu \mathrm{l}$. Analysis was done using the StepOnePlus Real-Time PCR System (Applied Biosystems). The initial $30 \mathrm{sec}$ denaturation at $95^{\circ} \mathrm{C}$ was followed by 40 cycles of $3 \mathrm{sec}$ denaturation at $95^{\circ} \mathrm{C}, 30 \mathrm{sec}$ annealing at $58^{\circ} \mathrm{C}$ and $30 \mathrm{sec}$ extension at $72^{\circ} \mathrm{C}$. The expression level of the soybean actin gene
(GenBank accession number: J01298) [22] was used to normalize target gene expression.

\section{Accession numbers}

Sequence data of the DFR2 gene were deposited in the DDBJ Data Libraries under accession nos. AB872212 (cDNA of Bay), AB872213 (cDNA of Clark-w4), AB872214 (cDNA of 222-A-3), AB872215 (cDNA of E30-D-1), AB872216 (genomic DNA of Clark) and AB872217 (genomic DNA of kw4).

\section{Results}

\section{Genetic analysis}

$\mathrm{F}_{1}$ plants derived from a cross between Harosoy- $w 4$ and kw4 had near white flowers (Table 3). All of the 116 plants of the $F_{2}$ population had near white flowers, suggesting that flower color of kw4 was controlled by the $w 4$ allele. $\mathrm{F}_{1}$ plants derived from a cross between 222-A3 and Clark-w4 had near white flowers. All of the 109 plants of the $\mathrm{F}_{2}$ population had near white flowers, suggesting that flower color of 222-A-3 was also controlled by the $w 4$ allele.

$\mathrm{F}_{1}$ plants derived from a cross between E30-D-1 and Clark had purple flowers. A total of 112 plants of the $F_{2}$ population segregated into 84 plants with purple flowers and 28 plants with light purple flowers. The segregation fitted a $3: 1$ ratio $\left(X^{2}=0.00, P=1.00\right)$ suggesting that a single gene controls flower color and that the allele for purple flower was dominant to that for light purple flower. $F_{1}$ plants derived from a cross between E30-D-1 
Table 3 Segregation of flower color in $F_{1}$ plants and $F_{2}$ populations derived from crosses between soybean cultivar Clark or near-isogenic lines (Harosoy-w4 and Clark-w4) and flower color variants, Glycine soja accession, kw4, and soybean mutant lines, 222-A-3 and E30-D-1 in Tsukuba, Japan

\begin{tabular}{|c|c|c|c|c|c|c|c|c|}
\hline \multirow{2}{*}{ Generation } & \multirow[t]{2}{*}{ Year } & \multicolumn{4}{|c|}{ Number of plants } & \multirow{2}{*}{$\begin{array}{l}\text { Expected } \\
\text { ratio }\end{array}$} & \multirow[t]{2}{*}{$\mathrm{x}^{2}$ value } & \multirow{2}{*}{$\begin{array}{c}\text { Probability } \\
\text { ( } P \text { value) }\end{array}$} \\
\hline & & Total & Purple & Light purple & Near white & & & \\
\hline kw4 & 2009 & 10 & - & - & 10 & - & - & - \\
\hline Harosoy-w4 (H-w4) & 2009 & 10 & - & - & 10 & - & - & - \\
\hline $\mathrm{H}-\mathrm{w} 4 \times \mathrm{kw} 4 \mathrm{~F}_{1}$ & 2009 & 5 & - & - & 5 & - & - & - \\
\hline $\mathrm{H}-\mathrm{w} 4 \times \mathrm{kw} 4 \mathrm{~F}_{2}$ & 2009 & 116 & - & - & 116 & - & - & - \\
\hline 222-A-3 (222) & 2010 & 10 & - & - & 10 & - & - & - \\
\hline Clark-w4 (C-w4) & 2010 & 10 & - & - & 10 & - & - & - \\
\hline $222 \times C-w 4 F_{1}$ & 2010 & 5 & - & - & 5 & - & - & - \\
\hline $222 \times C-w 4 F_{2}$ & 2010 & 109 & - & - & 109 & - & - & - \\
\hline E30-D-1 (E) & 2010 & 10 & - & 10 & - & - & - & - \\
\hline Clark (C) & 2010 & 10 & 10 & - & - & - & - & - \\
\hline$E \times C F_{1}$ & 2010 & 4 & 4 & - & - & - & - & - \\
\hline$E \times C F_{2}$ & 2013 & 112 & 84 & 28 & - & $3: 1$ & 0.00 & 1.00 \\
\hline$E \times C-W 4 F_{1}$ & 2010 & 3 & - & 3 & - & - & - & - \\
\hline $\mathrm{E} \times \mathrm{C}-w 4 \mathrm{~F}_{2}$ & 2010 & 111 & - & 82 & 29 & $3: 1$ & 0.08 & 0.78 \\
\hline
\end{tabular}

and Clark-w4 had light purple flowers. A total of 111 plants of the $F_{2}$ population segregated into 82 plants with light purple flowers and 29 plants with near white flowers. The segregation fitted a $3: 1$ ratio $\left(\chi^{2}=0.08, P=\right.$ 0.78 ) suggesting that the W4 locus controls the flower color and the allele for light purple flower was dominant to that for near white flower. All of the ten $F_{3}$ families derived from $\mathrm{F}_{2}$ plants with near white flowers had near white flowers. A total of 40 families derived from $F_{2}$ plants with light purple flowers segregated into 16 families fixed for light purple flowers and 24 families segregating for flower color (Table 4). The segregation fitted a $1: 2$ ratio $\left(X^{2}=0.80, P=0.37\right)$ confirming that an allele at the W4 locus controls flower color. The new allele was designated as w4-lp. The gene symbol was approved by the Soybean Genetics Committee. The dominance relationship of the alleles is $W 4>w 4-l p>w 4$.

\section{HPLC analysis}

Four anthocyanin components, A1: malvidin 3,5-di-Oglucoside, A2: petunidin 3,5-di-O-glucoside, A3: delphinidin 3,5-di-O-glucoside, A4: delphinidin 3-O-glucoside were detected in agreement with previous studies [11,12] (Table 5). Flowers of T369 contained 59.8\% of total anthocyanins compared with Clark. Less anthocyanins were detected in T321 (44.7\%) and E30-D-1 (39.3\%). Near white flowers of 222-A-3 had the lowest level of anthocyanins (15.6\%). Near white flowers of kw4 had only trace amount of the two components, A1 and A2. All cultivars and lines except for 222-A-3 and kw4 had all four components with the amounts decreasing in the following order: A1 > A2 > A3 > A4.

All cultivars and lines had eight flavonol glycoside components, F1 (kaempferol 3-O-gentiobioside), F2 (kaempferol 3-O-rutinoside), F3 (kaempferol 3-O-glucoside), F4 (kaempferol 3-O-glycoside), F5 (kaempferol 3-O-rhamnosyl-( $1 \rightarrow 2)$-[glucosyl- $(1 \rightarrow 6)$-galactoside]), F6 (quercetin 3-O-gentiobioside), F7 (kaempferol 7-O-glucoside), F8 (kaempferol 7-O-diglucoside) in accordance with previous studies [11-13] (Table 6). The total amounts of flavonol glycosides were not very different among cultivars and lines except for T369. F1 was most abundant and accounted for about $80 \%$ of flavonol glycosides in these cultivars and lines in accordance with previous

Table 4 Segregation of flower color in $F_{3}$ families derived from a cross between E30-D-1 and a soybean near-isogenic line Clark-w4 in 2012 and 2013 in Tsukuba, Japan

\begin{tabular}{|c|c|c|c|c|c|c|c|}
\hline \multirow{2}{*}{ Line } & \multicolumn{4}{|c|}{ Number of families } & \multirow{2}{*}{$\begin{array}{l}\text { Expected } \\
\text { ratio }\end{array}$} & \multirow[t]{2}{*}{$x^{2}$ value } & \multirow{2}{*}{$\begin{array}{c}\text { Probability } \\
\text { ( } P \text { value) }\end{array}$} \\
\hline & Total & Fixed for light purple & Segregating & Fixed for near white & & & \\
\hline 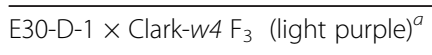 & 40 & 16 & 24 & - & $1: 2$ & 0.80 & 0.37 \\
\hline 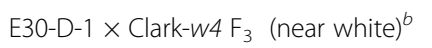 & 10 & - & - & 10 & - & - & - \\
\hline
\end{tabular}

${ }^{a} F_{3}$ families derived from $F_{2}$ plants with light purple flowers.

${ }^{b} \mathrm{~F}_{3}$ families derived from $\mathrm{F}_{2}$ plants with near white flowers. 
Table 5 Anthocyanin content [mean \pm SD $\left(\times 10^{3}\right)$ ] according to HPLC analysis of flower petals from soybean and Glycine soja in 2008 at Tsukuba, Japan

\begin{tabular}{lccccc}
\hline Line name & $\mathbf{A 1}^{\mathbf{a}}$ & $\mathbf{A 2}$ & $\mathbf{A 3}$ & $\mathbf{A 4}$ & Total \\
\hline Clark & $933 \pm 40$ & $538 \pm 21$ & $399 \pm 13$ & $255 \pm 20$ & $2,125 \pm 77$ \\
Bay & $1,745 \pm 326$ & $610 \pm 99$ & $323 \pm 62$ & $267 \pm 14$ & $2,945 \pm 331$ \\
222-A-3 & $142 \pm 28$ & $189 \pm 30$ & $0 \pm 0$ & $0 \pm 0$ & $331 \pm 16$ \\
E30-D-1 & $345 \pm 4$ & $241 \pm 20$ & $151 \pm 3$ & $98 \pm 65$ & $835 \pm 65$ \\
kW4 & $t^{\mathrm{b}}$ & $\mathrm{t}$ & $0 \pm 0$ & $0 \pm 0$ & - \\
T321 & $369 \pm 107$ & $255 \pm 22$ & $178 \pm 36$ & $148 \pm 4$ & $950 \pm 155$ \\
T369 & $513 \pm 32$ & $348 \pm 17$ & $232 \pm 44$ & $178 \pm 8$ & $1,271 \pm 89$ \\
LSD $_{0.05}$ & 239 & 76 & 58 & 48 & 268
\end{tabular}

${ }^{\mathrm{a} A 1:}$ malvidin 3,5-di-O-glucoside, A2: petunidin 3,5-di-O-glucoside, A3: delphinidin 3,5-di-O-glucoside, A4: delphinidin 3-O-glucoside. ${ }^{\mathrm{b}}$ Trace amount.

studies [11,12]. The amount of F2 was extremely low in kw4 and comprised only $0.1 \%$ of the total amount of flavonol glycosides. Flowers of T369 had substantially lower amount of flavonol glycosides (16.0\% of Clark).

Only one kind of dihydroflavonol (D1, aromadendrin 3-O-glucoside) was detected in all cultivars and lines except for T369 (Table 7). The amount varied from 57.4 (E30-D-1) to $163.8 \%$ (kw4) compared with Clark. In contrast, flower petals of T369 contained only $11.4 \%$ of D1 compared with Clark, in addition to two unique peaks corresponding to dihydroflavonols, D2 and D3 (Figure 3).

\section{Molecular cloning}

DNA fragments of about $1.1 \mathrm{~kb}$ were amplified by RTPCR in Clark, Bay, 222-A-3 and E30-D-1 (Figure 4). Fragments of about $1.4 \mathrm{~kb}$ were amplified from Clark-w4. No amplification product was observed in kw4. The coding region of DFR2 gene of Clark and Bay were 1065 bp long and they encoded 354 amino acids. Amino acids were identical except for two substitutions around the Cterminus at positions 338 (valine or glutamic acid) and 353 (arginine or glutamine). Comparison of nucleotide sequences between cDNA and genomic DNA of Clark revealed that the DFR2 gene has six exons and five introns similar to a previous report (Figure 5) [5].

Bay had a $\mathrm{T}$ at nucleotide position 29 which was absent in 222-A-3. This deletion probably generated a truncated polypeptide consisting of only 24 amino acids (Figure 6A and 6B). The polypeptide lacked the NADPH binding domain [23]. In E30-D-1, a single base was substituted from $\mathrm{G}$ to $\mathrm{A}$ at nucleotide position 116 compared with Bay (Figure 6C). The base-substitution altered amino acid at position 39 from arginine to histidine. The $5^{\prime}$ upstream region of E30-D-1 was identical with that of Bay and Clark. In Clark-w4, cDNA had a 344-bp insertion compared with Clark and Bay. The insertion corresponded to the fourth intron with five nucleotide substitutions compared with Clark, suggesting that the fourth intron was retained in Clark-w4. In Clark-w4, a single-base $\mathrm{G}$ at the start of the fourth intron was changed to A compared with the genome sequence of Clark (Figure 6D). The base substitution may have abolished the $5^{\prime}$ splice site (GT) resulting in the retention of the intron (Figure 5). The retention caused a mutation from amino acid position 217 and premature translation termination at amino acid position 227 (Figure 6D).

In kw4, transcripts of the DFR2 gene in the flower petals were not detected by RT-PCR. The genomic fragment containing the entire coding region was amplified by PCR. Six exons and five introns were assumed similar to Clark (Figure 5). The amino acid sequence was identical with that of Clark. A 367-bp fragment was deleted in the third intron of kw4 (Figure 5). The 5' upstream region of kw4 had six single-base substitutions, three single-base indels, two two-base indels and a three-base alteration including one indel (Additional file 1: Figure S1).

\section{CAPS analysis}

PCR with CAPS primers generated amplified products of 377 bp in Bay, Clark, Clark-w4, 222-A-3 and E30-D-1 (Figure 7). Digestion with $B s r G I$ generated a band of

Table 6 Flavonol glycoside content [mean \pm SD $\left(\times 10^{3}\right)$ ] according to HPLC analysis of flower petals from soybean and Glycine soja in 2008 at Tsukuba, Japan

\begin{tabular}{|c|c|c|c|c|c|c|c|c|c|}
\hline Line name & $\mathrm{F} 1^{\mathrm{a}}$ & F2 & F3 & F4 & F5 & F6 & F7 & F8 & Total \\
\hline Clark & $9,432 \pm 103$ & $772 \pm 34$ & $177 \pm 6$ & $441 \pm 26$ & $353 \pm 38$ & $138 \pm 10$ & $13 \pm 0$ & $128 \pm 13$ & $11,454 \pm 177$ \\
\hline Bay & $8,508 \pm 278$ & $788 \pm 52$ & $162 \pm 5$ & $246 \pm 10$ & $429 \pm 26$ & $131 \pm 8$ & $53 \pm 0$ & $179 \pm 15$ & $10,496 \pm 385$ \\
\hline $222-A-3$ & $7,836 \pm 426$ & $698 \pm 39$ & $134 \pm 9$ & $275 \pm 33$ & $459 \pm 42$ & $124 \pm 2$ & $323 \pm 55$ & $365 \pm 15$ & $10,214 \pm 477$ \\
\hline E30-D-1 & $8,001 \pm 491$ & $732 \pm 37$ & $168 \pm 78$ & $335 \pm 24$ & $465 \pm 20$ & $117 \pm 32$ & $274 \pm 43$ & $318 \pm 56$ & $10,409 \pm 630$ \\
\hline kw4 & $10,947 \pm 386$ & $16 \pm 2$ & $432 \pm 5$ & $695 \pm 26$ & $802 \pm 50$ & $154 \pm 7$ & $354 \pm 52$ & $417 \pm 38$ & $13,816 \pm 533$ \\
\hline T321 & $9,417 \pm 476$ & $805 \pm 50$ & $159 \pm 17$ & $371 \pm 20$ & $523 \pm 16$ & $100 \pm 2$ & $174 \pm 10$ & $287 \pm 12$ & $11,838 \pm 598$ \\
\hline T369 & $703 \pm 9$ & $214 \pm 26$ & $102 \pm 2$ & $135 \pm 1$ & $243 \pm 5$ & $151 \pm 2$ & $130 \pm 6$ & $158 \pm 16$ & $1,837 \pm 55$ \\
\hline $\mathrm{LSD}_{0.05}$ & 647 & 69 & 56 & 41 & 58 & 24 & 60 & 52 & 827 \\
\hline
\end{tabular}

${ }^{\mathrm{a}} \mathrm{F} 1$ (kaempferol 3-O-gentiobioside), F2 (kaempferol 3-O-rutinoside), F3 (kaempferol 3-O-glucoside), F4 (kaempferol 3-O-glycoside), F5 (kaempferol 3-O-rhamnosyl$(1 \rightarrow 2)$-[glucosyl-(1 $\rightarrow 6)$-galactoside]), F6 (quercetin 3-O-gentiobioside), F7 (kaempferol 7-O-glucoside), F8 (kaempferol 7-O-diglucoside). 
Table 7 Dihydroflavonol content [mean \pm SD $\left(\times 10^{3}\right)$ ] according to HPLC analysis of flower petals from soybean and Glycine soja in 2008 at Tsukuba, Japan

\begin{tabular}{lcccc}
\hline Line name & $\mathbf{D 1}^{\mathbf{a}}$ & $\mathbf{D 2}^{\mathbf{b}}$ & $\mathbf{D 3}^{\mathbf{b}}$ & Total \\
\hline Clark & $843 \pm 53$ & $0 \pm 0$ & $0 \pm 0$ & $843 \pm 53$ \\
Bay & $758 \pm 83$ & $0 \pm 0$ & $0 \pm 0$ & $758 \pm 83$ \\
222-A-3 & $593 \pm 40$ & $0 \pm 0$ & $0 \pm 0$ & $593 \pm 40$ \\
E30-D-1 & $484 \pm 24$ & $0 \pm 0$ & $0 \pm 0$ & $484 \pm 24$ \\
kw4 & $1,381 \pm 58$ & $0 \pm 0$ & $0 \pm 0$ & $1,381 \pm 58$ \\
T321 & $646 \pm 22$ & $0 \pm 0$ & $0 \pm 0$ & $646 \pm 22$ \\
T369 & $96 \pm 8$ & $153 \pm 39$ & $54 \pm 10$ & $303 \pm 54$ \\
LSD $_{0.05}$ & 86 & 27 & 7 & 94 \\
\hline D1: & & & &
\end{tabular}

${ }^{\mathrm{a} D 1}$ : aromadendrin 3-O-glucoside.

${ }^{\mathrm{b}} \mathrm{D} 2$, D3: unidentified dihydroflavonols.

194 bp in E30-D-1, whereas the bands were not digested in the other materials (Figure 7). CAPS analysis of an $\mathrm{F}_{2}$ population derived from a cross between E30-D-1 and Clark-w4 together with the $\mathrm{F}_{3}$ progeny tests revealed that plants fixed with light purple flowers had only a shorter band, plants fixed with near white flowers had only a longer band and plants segregating for flower color had both bands. Thus, the CAPS marker co-segregated with flower color.

\section{Quantitative real-time PCR}

Results of real-time PCR are presented in Figure 8. Transcript level of T321 was low and 16.8\% of Bay. Transcript levels of 222-A-3, E30-D-1 and Clark-w4 were much lower at 7.7, 3.8 and $3.7 \%$, respectively. Transcripts of the DFR2 gene of kw4 were not detected by real-time PCR. In contrast to the above flower color variants, the transcript level of T369 was about 2.3 times of Bay (Figure 8).

\section{Discussion}

Previous studies revealed that the $W 4$ gene was mutated in flower color variants, Clark-w4, T321 and T369 [3,5]. In this study, complementation tests revealed that the flower color of 222-A-3 and E30-D-1, and that of a G. soja accession, kw4, was also controlled by this gene. Amino acid polymorphism or null expression of the DFR2 gene was associated with flower color variation.

In 222-A-3, a single-base deletion caused a frame-shift mutation from amino acid position 11; this is expected to produce a truncated polypeptide of only 24 amino acids that lacked the NADPH binding domain. Thus, the DFR2 transcript of 222-A-3 may be nonfunctional. In Clark-w4, the first nucleotide of the fourth intron was substituted from $\mathrm{G}$ to A. The base substitution in Clarkw4 may have abolished the $5^{\prime}$ splice site (spliceosome recognition site). Retention of the fourth intron caused a frame-shift mutation and changed subsequent amino

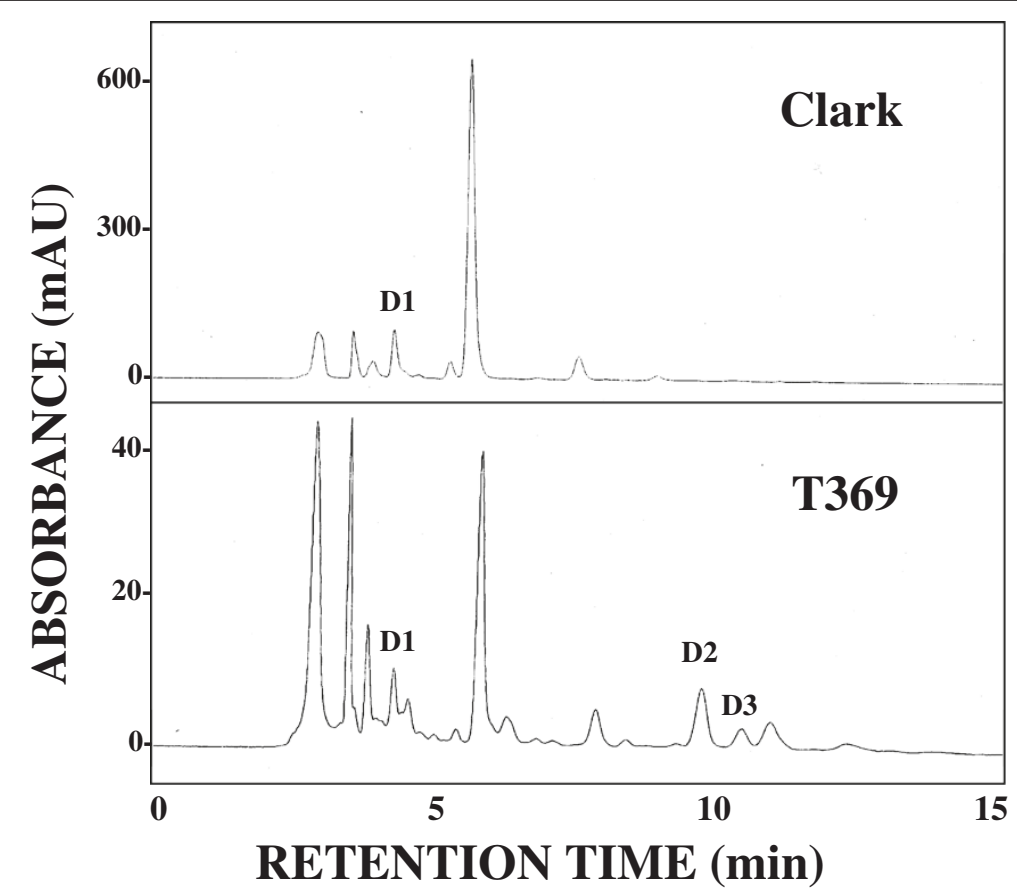

Figure 3 HPLC chromatogram of dihydroflavonols extracted from flower petals of a soybean cultivar Clark and T369. A total of 200 mg of banner petals was extracted with $2 \mathrm{ml}$ of $\mathrm{MeOH}$. Eluents: $\mathrm{MeCN} / \mathrm{H}_{2} \mathrm{O} / \mathrm{H}_{3} \mathrm{BO}_{3}$ (22:78:0.2). Flow-rate: $1.0 \mathrm{ml} / \mathrm{min}$. Injection: $10 \mu \mathrm{l}$. Detection: $290 \mathrm{~nm}$. D1, aromadendrin 3-O-glucoside; D2 and D3, unidentified dihydroflavonols. 


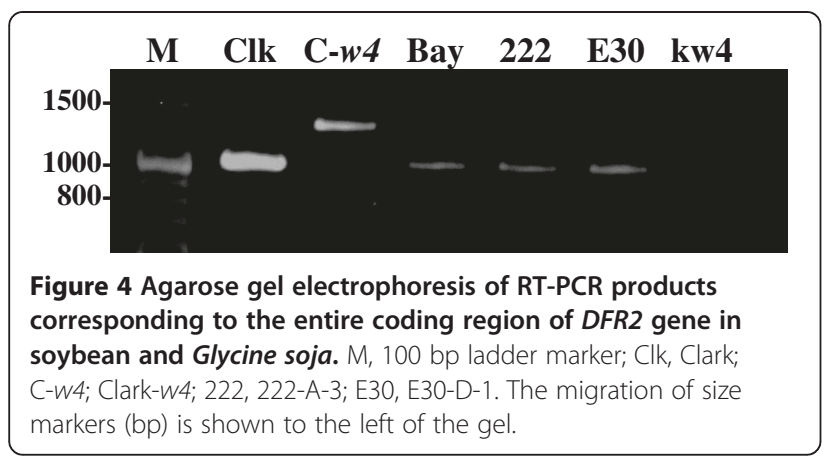

acids. Translation was prematurely terminated at amino acid position 227. DFR genes have many amino acids conserved across plant species in the downstream of the mutation [24]. The results strongly suggest that the $D F R 2$ gene of Clark-w4 is not functioning. In kw4, the DFR2 gene was not expressed in flower petals. A 367-bp fragment was deleted from the third intron of this gene in kw4. However, it is not clear whether the deletion in the intron might be responsible for null gene expression. Therefore, we investigated the $5^{\prime}$ upstream region to check if any mutation occurred in the promoter region. There were many nucleotide polymorphisms in the $5^{\prime}$ upstream region; six single-base substitutions, three single-base indels, two two-base indels and a three-base alteration including an indel. The accumulation of a substantial number of mutations in the promoter region, which is probably the reason for non-transcription of this locus in kw4, is characteristic of genes that are being deactivated into pseudogenes. Promoter assays may be necessary to determine which polymorphism is critical for gene expression. Features of DNA sequences in Clark-w4, 222-A-3 and kw4 strongly suggest that complete lossof-function of DFR2 gene may lead to substantial reduction of anthocyanins and near white flowers.

Soybean has three variants of $D F R$ genes, $D F R 1, D F R 2$ and $D F R 3$ [17]. The function of $D F R 2$ may be partially supplemented by the activity of other DFR genes depending on environmental conditions. The transcript level of Clark-w4 and 222-A-3 was substantially lower than that of Bay, probably because of nonsense-mediated mRNA decay, a surveillance mechanism to eliminate aberrant mRNA transcripts that contain premature stop codons [25].

The $5^{\prime}$ upstream regions of the DFR2 gene in E30-D-1, Bay and Clark were identical. In the first exon of E30-D-1, however, a single-base substitution altered an amino acid at position 39 from arginine to histidine. The position of the residue was slightly downstream of the NADPH binding region. No catalytic domain has been assigned to the region, but the arginine residue is conserved across eight plant species [24]. Further, CAPS marker to detect the base substitution co-segregated with flower color. These results suggest that the amino acid substitution might have affected transcript abundance and/or DFR function resulting in reduced anthocyanin contents and paler flower color. Transgenic experiments may be necessary to ascertain the functional importance of this residue.

Flavonol glycoside content in flower petals of T321 was similar to that of Clark. In contrast, that of T369 was 16.0\% of Clark. The DFR2 gene was over-expressed in flower petals of T369 but it was barely expressed in T321. The reduction of flavonol glycosides in T369 may be explained by substrate competition between over-expressed DFR and flavonol synthase (Figure 1). Flower petals of T369 contained substantially lower amounts of D1 but it had unique dihydroflavonol components, D2 and D3, that are absent in the soybean and G. soja accessions analyzed so far. Overexpression of $D F R 2$ gene may be responsible for the unique dihydroflavonol composition. Chemical structure of D2 and D3 should be determined to investigate the novel features of DFR2 function displayed by T369.

In T321 and T369, Tgm9 was excised from the second intron of the DFR2 gene, leaving behind 4- and 0-bp footprints, respectively [5]. A $5^{\prime}$ end fragment of $\operatorname{Tgm} 9$ (944 bp) was integrated at the $1043 \mathrm{bp}$ upstream of the transcription start site in T321. A fragment of $\operatorname{Tgm} 9$ was inserted at the 1034 bp upstream of the transcription start site in T369 [5]. In both cases, excision of $\operatorname{Tg} m 9$

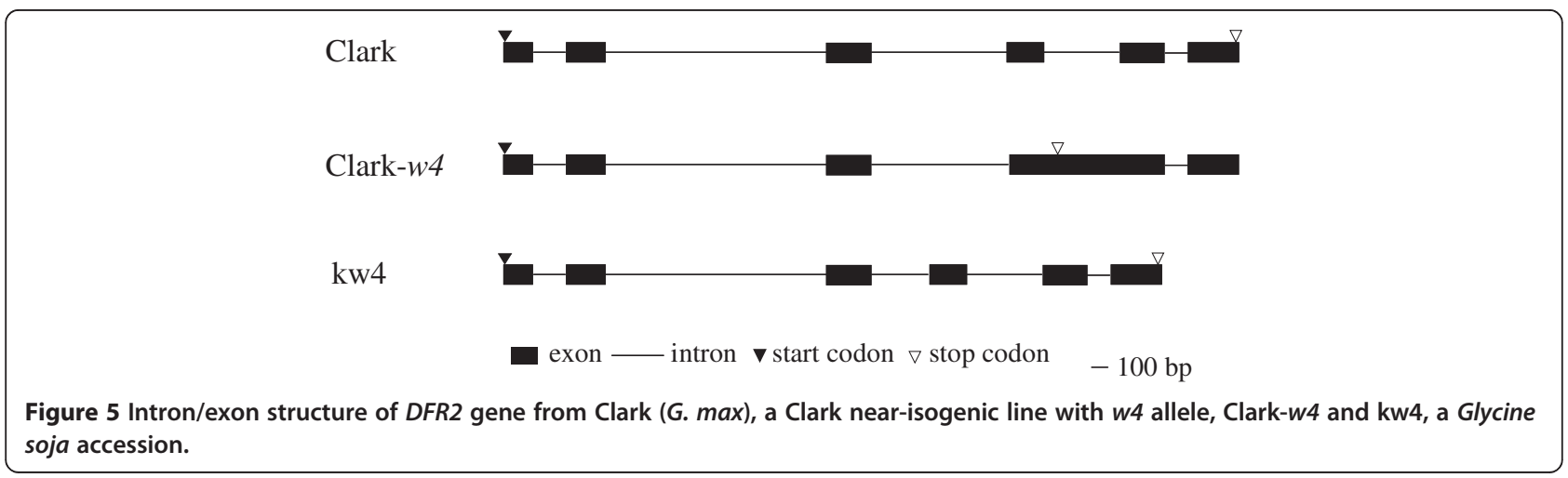




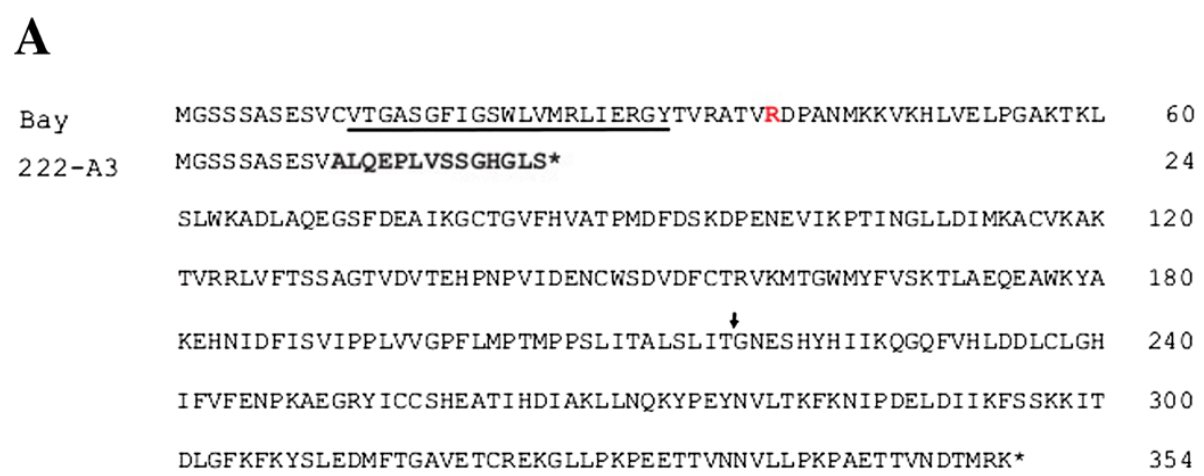

B

Bay

$222-\mathrm{A} 3$ GAAAGTGTTTGCGTTACAGGAGCCTCTGGTTTCATCGGGTCAT GGCTTGTCATGA

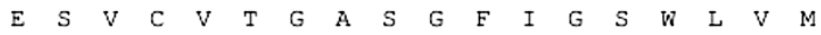
GAAAGTG-TTGCGTTACAGGAGCCTCTGGTTTCATCGGGTCATGGCTTGTCATGA

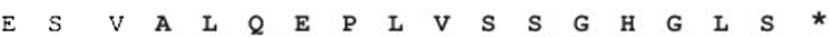

Bay

E30-D-1
GGCTACACGGTCCGAGCCACTGTACGCGATCCAGCTAACATGAAGAAG

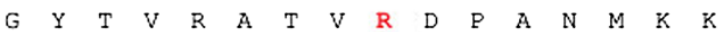
BsrGI GGCTACACGGTCCGAGCCACTGTACACGATCCAGCTAACATGAAGAAG

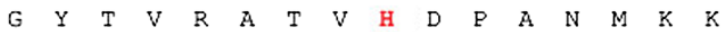

\section{D \\ Clark \\ Clark-w 4

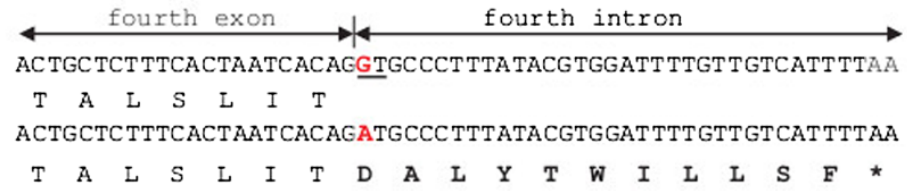

Figure 6 Nucleotide and amino acid polymorphisms of the DFR2 gene in flower color variants of soybean. (A) Amino acid sequence of Bay and 222-A-3. Amino acids polymorphic in 222-A-3 are shown in bold. NADPH binding domain is underlined. The polymorphic amino acid in E30-D-1 is shown in red font. End of the fourth exon is indicted by an arrow. (B) Alignment of partial cDNA and amino acid sequences from Bay and 222-A-3. Polymorphic nucleotides are shown in red font. The polymorphic amino acids in 222-A-3 are shown in bold. (C) Alignment of partial CDNA and amino acid sequences from Bay and E30-D-1. Polymorphic nucleotides and amino acids are shown in red font. Restriction site used for CAPS analysis is underlined. (D) Alignment of partial nucleotide and amino acid sequences around the end of the fourth exon of Clark and the corresponding region of Clark-w4. Polymorphic nucleotides are shown in red font. Nucleotides common in the 5' splice site are underlined. Amino acids polymorphic in Clark-w4 are shown in bold.

may not be the cause of flower color change, because $\operatorname{Tg} m 9$ resides in the intron, and footprints, if any, are not likely to substantially affect gene expression. Instead, re-insertion into the promoter region is more likely responsible. The upstream promoter regions of structural anthocyanin biosynthesis genes contain cis regulatory elements that affect pigmentation patterns or intensity [5]. It is interesting to determine the role of 9-bp differences in the Tgm9 integration site in the expression of the DFR2 gene. Detailed promoter assays may be necessary to identify the cis element regulating the expression of this gene.

DFR2 gene of soybean controls intensity and distribution of pigmentation in flower petals. Mutation of the gene results in unique flavonoid composition and a wide variety of flower color patterns, from near white, light purple, dilute purple to pale. 

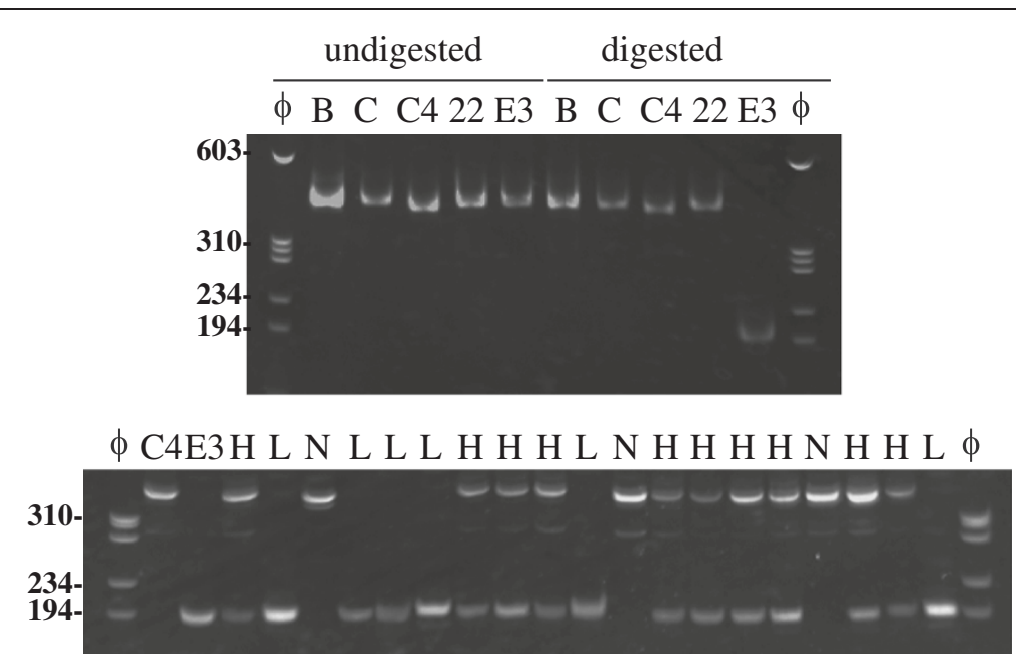

Figure 7 Results of CAPS analysis of DFR2 gene in soybean. (Upper panel) Results of CAPS analysis for flower color variants. PCR products amplified with CAPS primers were digested by BsrGl and the digests were separated on an 8\% polyacrylamide gel. $\phi$, molecular marker $\phi \times 174 /$ Haelli; B, Bay; C, Clark; C4, Clark-w4; 22, 222-A3; E3, E30-D-1. (Lower panel) Results of CAPS analysis in an F population derived from a cross between E30-D-1 and Clark-w4. \$, \$x174/Haelli; C4, Clark-w4; E3, E30-D-1; H, F plants segregating for flower color; L, $F_{2}$ plants fixed for light purple flower; $\mathrm{N}, \mathrm{F}_{2}$ plants fixed for near white flower. The migration of size markers is shown to the left of the gel.

\section{Conclusions}

The flower colors of 222-A-3, Clark-w4, E30-D-1, kw4, T321 and T369 were controlled by the W4 gene encoding DFR2. In 222-A-3, a single-base deletion probably produced a truncated polypeptide consisting of 24 amino acids. In Clark- $w 4$, base substitution of the first nucleotide of the fourth intron abolished the $5^{\prime}$ splice site, resulting in the retention of the intron. The DFR2 gene of kw4 was not expressed. The above results suggest that complete loss-of-function of $D F R 2$ gene leads to near white flowers. Flower color of E30-
D-1 was controlled by a new allele of the W4 locus, $w 4-l p$. In E30-D-1, a single-base substitution changed an amino acid at position 39 from arginine to histidine. In T369, expression of DFR2 gene was 2.3 times that of purple flowers, and the flower petals contained unique dihydroflavonols which are absent in other G. max and G. soja accessions. Thus, mutations of DFR2 gene results in unique flavonoid compositions and a wide variety of flower color patterns in soybean, ranging from near white, light purple, dilute purple to pale.

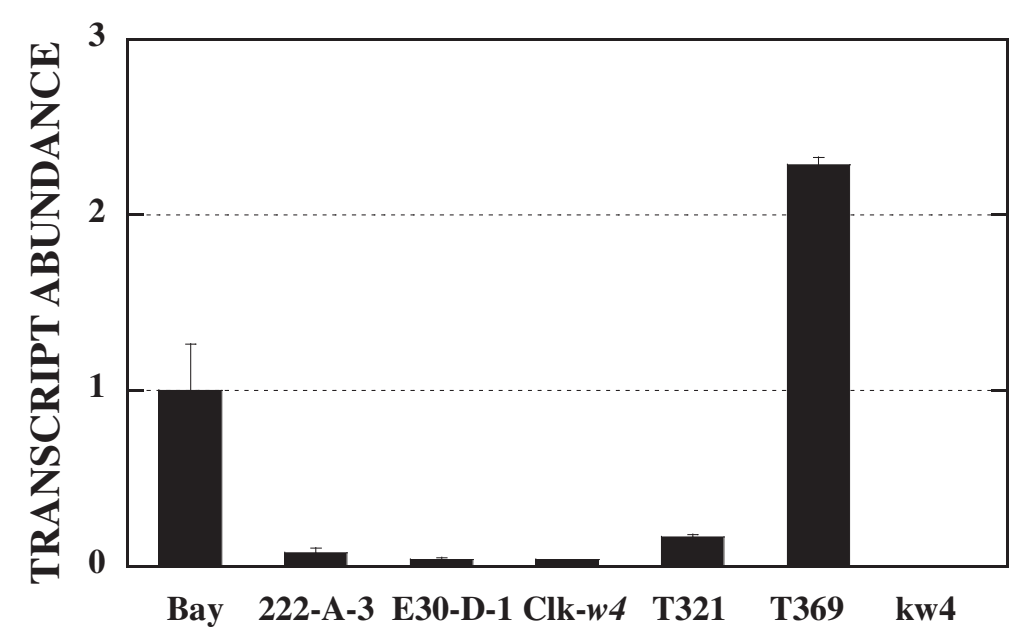

Figure 8 Expression of DFR2 gene relative to the cultivar Bay in flower petals of soybean and Glycine soja. Transcript levels were standardized to the transcript level of actin. The means and SDs from three biological replications are exhibited. 


\section{Additional file}

Additional file 1: Figure S1. Alignment of the $5^{\prime}$ upstream region of DFR2 gene in soybean cultivar Clark and a Glycine soja accession kw4. Polymorphic nucleotides are shown in red font. Coding sequence is underlined.

\section{Abbreviations}

$\mathrm{CHI}$ : Chalcone isomerase; CHS: Chalcone synthase; DFR: Dihydroflavonol 4reductase; F3H: Flavanone 3-hydroxylase; F3'H: Flavonoid 3'-hydroxylase; F3'5' H: Flavonoid 3'5'-hydroxylase; FLS: Flavonol synthase; G. soja: Glycine soja; HPLC: High performance liquid chromatography; LDOX: Leucoanthocyanidin dioxygenase; NIL: Near-isogenic line.

\section{Competing interests}

The authors declare that they have no competing interests.

\section{Authors' contributions}

RT designed and supervised the research. YM and TI performed chemical analysis. TA discovered and provided novel mutant lines. FY and SD performed molecular biology experiments. RT, TA, FRR and TRT performed genetic analysis. All authors read and approved the final manuscript.

\section{Acknowledgements}

We thank Dr. R.L. Nelson at USDA/ARS Univ of Illinois for supplying the seeds of the NILs and the Genetic Type Collections, and Dr. Jun Abe (Hokkaido University, Japan) and Dr. Euho Park (Yeungnam University, South Korea) for the seeds of kw4. We are grateful to Dr. Joseph G. Dubouzet (New Zealand) for critical reading of the manuscript. This study was partially supported by the scholarship from the China Scholarship Council to FY and SD, and the Japanese Government (MEXT) Scholarship to FRR and TRT.

\section{Author details}

1 Graduate School of Life and Environmental Sciences, University of Tsukuba, Tsukuba, Ibaraki 305-8518, Japan. ²Department of Botany, National Museum of Nature and Science, Tsukuba, Ibaraki 305-0005, Japan. ${ }^{3}$ Laboratory of Plant Genetics and Breeding, Faculty of Agriculture, Saga University, Honjo-machi, Saga 840-8502, Japan. ${ }^{4}$ National Institute of Crop Science, Tsukuba, Ibaraki 305-8518, Japan.

Received: 4 December 2013 Accepted: 26 February 2014 Published: 6 March 2014

\section{References}

1. Palmer RG, Pfeiffer TW, Buss GR, Kilen TC: Qualitative genetics. In Soybeans: Improvement, Production, and Uses. 3rd edition. Edited by Boerma HR, Specht JE. Madison, WI: American Society of Agronomy; 2004:137-233.

2. Takahashi R, Matsumura H, Oyoo ME, Khan NA: Genetic and linkage analysis of purple-blue flower in soybean. J Hered 2008, 99:593-597.

3. Hartwig $\mathrm{EE}$, Hinson $\mathrm{K}$ : Inheritance of flower color of soybeans. Crop SCi 1962, 2:152-153.

4. Fasoula DA, Stephens PA, Nickell CD, Vodkin LO: Cosegregation of purple-throat flower color with dihydroflavonol reductase polymorphism in soybean. Crop Sci 1995, 35:1028-1031.

5. Xu M, Brar HK, Grosic S, Palmer RG, Bhattacharyya MK: Excision of an active CACTA-like transposable element from DFR2 causes variegated flowers in soybean [Glycine max (L.) Merr.]. Genetics 2010, 184:53-63.

6. Takahashi R, Benitez ER, Oyoo ME, Khan NA, Komatsu S: Nonsense mutation of an MYB transcription factor is associated with purple-blue flower color in soybean. J Hered 2011, 102:458-463.

7. Takahashi R, Githiri SM, Hatayama K, Dubouzet EG, Shimada N, Aoki T, Ayabe S, Iwashina T, Toda K, Matsumura H: A single-base deletion in soybean flavonol synthase gene is associated with magenta flower color. Plant Mol Biol 2007, 63:125-135.

8. Takahashi R, Yamagishi N, Yoshikawa N: A MYB transcription factor controls flower color in soybean. J Hered 2013, 104:149-153.

9. Zabala G, Vodkin LO: The wp mutation of Glycine max carries a gene-fragment-rich transposon of the CACTA superfamily. Plant Cell 2005, 17:2619-2632.
10. Zabala G, Vodkin LO: A rearrangement resulting in small tandem repeats in the $\mathrm{F}^{\prime} \mathrm{S}^{\prime} \mathrm{H}$ gene of white flower genotypes is associated with the soybean W1 locus. Crop Sci 2007, 47(2):S113-S124

11. Iwashina T, Githiri SM, Benitez ER, Takemura T, Kitajima J, Takahashi R: Analysis of flavonoids in flower petals of soybean near-isogenic lines for flower and pubescence color genes. J Hered 2007, 98:250-257.

12. Iwashina T, Oyoo ME, Khan NA, Matsumura H, Takahashi R: Analysis of flavonoids in flower petals of soybean flower color variants. Crop Sci 2008, 48:1918-1924

13. Takahashi R, Dubouzet JG, Matsumura H, Yasuda K, Iwashina T: A new allele of flower color gene $W 1$ encoding flavonoid $3{ }^{\prime} 5^{\prime}$-hydroxylase is responsible for light purple flowers in wild soybean Glycine soja. BMC Plant Biol 2010, 10:155.

14. Palmer RG, Hedges BR, Benavente RS, Groose RW: w4-mutable line in soybean. Dev Genet 1989, 10:542-551.

15. Palmer RG, Groose RW: A new allele at the $W 4$ locus drived from the w4-m mutable alele in soybean. J Hered 1993, 84:297-300.

16. Xu M, Palmer RG: Genetic analysis and molecular mapping of a pale flower allele at the W4 locus in soybean. Genome 2005, 48:334-340.

17. Yang K, Jeong N, Moon JK, Lee YH, Lee SH, Kim HM, Hwang CH, Back K, Palmer RG, Jeong SC: Genetic analysis of genes controlling natural variation of seed coat and flower colors in soybean. $J$ Hered 2010, 101:757-768.

18. Chen YW, Nelson RL: Identification and characterization of a white-flowered wild soybean plant. Crop Sci 2004, 44:339-342.

19. Anai T: Potential of a mutant-based reverse genetic approach for functional genomics and molecular breeding in soybean. Breeding $\mathrm{SCl}$ 2012, 61:462-467.

20. Bernard RL, Nelson RL, Cremeens CR: USDA soybean genetic collections: Isoline collection. Soybean Genetics Newsletter 1991, 18:27-57.

21. Murray MG, Thompson WF: Rapid isolation of high molecular-weight plant DNA. Nucleic Acids Res 1980, 8:4321-4325.

22. Shah DM, Hightower RC, Meagher RB: Genes encoding actin in higher plants: intron positions are highly conserved but the coding sequences are not. J Mol Appl Genet 1983, 2:111-126

23. Lacombe E, Hawkins S, Van Doorsselaere J, Piquemal J, Goffner D, Poeydomenge O, Boudet AM, Grima-Pettenati J: Cinnamoyl CoA reductase, the first committed enzyme of the lignin branch biosynthetic pathway: cloning, expression and phylogenetic relationships. Plant J 1997, 11:429-441

24. Shimada S, Takahashi K, Sato Y, Sakuta M: Dihydroflavonol 4-reductase cDNA from non-anthocyanin-producing species in the Caryophyllales. Plant Cell Physiol 2004, 45:1290-1298.

25. Chang YF, Imam JS, Wilkinson ME: The nonsense-mediated decay RNA surveillance pathway. Annu Rev Biochem 2007, 76:51-74.

doi:10.1186/1471-2229-14-58

Cite this article as: Yan et al:: Allelic variation of soybean flower color gene W4 encoding dihydroflavonol 4-reductase 2. BMC Plant Biology 2014 14:58

\section{Submit your next manuscript to BioMed Central and take full advantage of:}

- Convenient online submission

- Thorough peer review

- No space constraints or color figure charges

- Immediate publication on acceptance

- Inclusion in PubMed, CAS, Scopus and Google Scholar

- Research which is freely available for redistribution 